\title{
ANALISIS FAKTOR-FAKTOR YANG MEMPENGARUHI FOREIGN DIRECT INVESTMENT (FDI) DI SINGAPURA TAHUN 2004-2019
}

\author{
Erika Bela Agustin', Sri Muljaningsih², Kiki Asmara ${ }^{3}$ \\ ${ }^{1,2,3}$ Program Studi Ekonomi Pembangunan, Fakultas Ekonomi dan Bisnis, \\ Universitas Pembangunan Nasional "Veteran" Jawa Timur, \\ Surabaya, Indonesia \\ belaerika07@gmail.com
}

\begin{abstract}
Abstrak
Jumlah investasi asing langsung di ASEAN khususnya di Singapura, telah meningkat secara drastis selama beberapa dekade terakhir. Singapura berhasil menempati peringkat pertama sebagai penerima FDI tertinggi dibanding negara anggota ASEAN lainnya. Tujuan dari dilakukannya penelitian ini adalah untuk mengetahui pengaruh GDP (Gross Domestic Product), Inflasi, Trade Openness, dan Lending Interest Rate terhadap Foreign Direct Investment (FDI) di Singapura pada periode 2004-2019. Dengan menggunakan metode analisis kuantitatif yakni analisis regresi linier berganda dan data yang digunakan sebesar 15 data dari masing-masing variabel. Variabel bebas dalam penelitian ini ialah GDP(X1), inflasi(X2), Trade Openness(X3), Lending Interest Rate(X4). Sedangkan variabel terikatnya adalah Foreign Direct Investment Singapura periode 2004-2019. Hasil dari penelitian ini ialah ada pengaruh positif signifikan pada variabel GDP terhadap FDI di Singapura dan ada pengaruh negatif signifikan pada variabel Lending Interest Rate terhadap FDI di Singapura. Sedangkan variabel Inflasi dan Trade Openness dinyatakan tidak memiliki pengaruh yang signifikan terhadap FDI di Singapura.
\end{abstract}

Kata Kunci: PDB, Inflasi, Tingkat Suku Bunga, Keterbukaan Perdagangan.

\begin{abstract}
The amount of Foreign Direct Investment (FDI) in ASEAN, especially in Singapore, has been increasing drastically over the last few decades. Singapore managed to rank first as the highest recipient of FDI compared to other ASEAN member countries. This research aims to determine the effect of GDP (Gross Domestic Product), Inflation, Trade Openness, and Lending Interest Rate on Foreign Direct Investment (FDI) in Singapore during 2004-2019. By using quantitative analysis methods, namely multiple linear regression analysis and used 15 data from each variable. The independent variables in this research are GDP (X1), Inflation (X2), Lending Interest Rate (X3), Trade Openness (X4). While the dependent variable is Singapore's Foreign Direct Investment during 2004-2019. The results showed that simultaneously the variables Gross Domestic Product, Inflation, Lending Interest Rate, and Trade Openness had a significant effect on Foreign Direct Investment (FDI) in Singapore. The GDP (Gross Domestic Product) variable partially has a significant effect and has a positive relationship with Foreign Direct Investment (FDI) in Singapore. Inflation variable partially has no significant effect and has a positive relationship with Foreign Direct Investment (FDI) in Singapore. Lending Interest Rate variable partially has a significant effect and has a negative relationship with Foreign Direct Investment (FDI) in Singapore. And Trade Openness variable partially has no significant effect and has a negative relationship with Foreign Direct Investment (FDI) in Singapore.
\end{abstract}

Keywords: GDP, Inflation,, Lending Interest Rate, Trade Openness 


\section{PENDAHULUAN}

Negara-negara di wilayah asia tenggara yaitu Indonesia, Malaysia, Singapura, Thailand, Filipina, Brunei Darussalam, Vietnam, Laos, Myanmar, dan Kamboja bergabung dalam organisasi geopolitik dan ekonomi bernama ASEAN (Association of Southeast Asian Nation) yang didirikan di Bangkok pada tahun 1967. Arus Foreign Direct Investment di wilayah Asia Tenggara cenderung berkembang pesat semenjak tahun 1990'an. Pada tahun 2015 menurut UNCTAD perkembangan Foreign Direct Investment di wilayah Asia Tenggara terjadi peningkatan sebesar 5\% mencapai 133 milliar dollar AS.

Pada deklarasi ASEAN Bali Concord II tahun 2003 dinyatakan pembentukan integrasi ekonomi wilayah yang diharapkan dapat menciptakan pasar tunggal dan produksi melalui ASEAN Economic Community (AEC). Tujuan dibentuknya ASEAN Economic Community (AEC) yaitu untuk mewujudkan arus free investment dan membebaskan arus modal. Menurut Yap (2015) disusunnya ASEAN Economic Community (AEC) adalah untuk menarik lebih banyak FDI ke wilayah Asia Tenggara, tindakan standar yang dilakukan untuk menarik FDI berkaitan dengan infrastruktur yang baik, tingginya kualitas sumber daya manusia, baiknya tata Kelola, serta unsur penting yang tertera pada ASEAN Economic Community (AEC) yaitu penghapusan hambatan peraturan terhadap arus modal internasional dan partisipasi investor asing pada perusahaan domestik.

Pada ASEAN Investment Forum, yang diadakan pada tahun 2011. Kegiatan ini bertujuan untuk diciptakannya free flow investment yang berhubungan dengan besarnya arus investasi secara langsung atau FDI diwilayah ASEAN. Yang artinya kegiatan ekonomi ASEAN tidak hanya soal perdagangan melainkan juga investasi atau FDI. Dapat disimpulkan bahwa kegiatan yang diadakan oleh ASEAN sering mencakup tujuan untuk meningkatkan perdagangan dan investasi khususnya FDI bagi negara-negara anggotanya.

FDI sendiri adalah salah satu instrumen dalam sistem ekonomi yang persebarannya telah mencakup berbagai negara. FDI sering disebut sebagai investasi yang dilakukan oleh perusahaan negara pelaku penanam modal (home country) kepada negara tujuan investasi (host country). Pada dasarnya, FDI suatu negara diikuti oleh keunggulan yang dimiliki oleh negara tersebut agar dapat menarik minat investor asing. Salah satunya ialah kemudahan dalam berinvestasi (Geringer et al., 2014, p. 102).

Menurut data ASEAN Investment Report (2019) pada tahun 2018, peringkat FDI di ASEAN yang pertama diduduki oleh Singapura dengan nilai sebesar 77.6 Billions of dollars, diikuti oleh
Indonesia dengan nilai sebesar 22.0 Billion of dollars, Vietnam dengan nilai sebesar 15.5 Billion of dollars, Thailand dengan nilai sebesar 13.2 Billion of dollars, Filipina dengan nilai sebesar 9.8 Billion of dollars, selanjutnya Malaysia dengan nilai sebesar 8.1 Billion of dollars, Myanmar dengan nilai sebesar 3.6 Billion of dollars, lalu Kamboja dengan nilai sebesar 3.1 Billion of dollars, dan peringkat terakhir diduduki oleh laos dengan nilai FDI sebesar 1,3 Billion of dollars. Dapat disimpulkan bahwa Negara Singapura sebagai satu-satunya negara maju yang menjadi anggota ASEAN dengan arus FDI paling tinggi. Pada tahun 2015 arus FDI disingapura tercatat sebesar 59,7 Billion of dollars, tahun 2016 sebesar 73,9 Billion of dollars, tahun 2017 sebesar 75,7 Billion of dollars, dan tahun 2018 sebesar 77,6 Billion of dollars. (ASEAN Investment Report, 2019)

Beberapa penelitian terdahulu cukup banyak yang melakukan penelitian mengenai determinan FDI pada negara anggota ASEAN dan khususnya negara Singapura dengan menggunakan variabel ekonomi, dan berpengaruh terhadap FDI. Variabel yang sering digunakan untuk membuktikan pengaruhnya terhadap Foreign Direct Investment di wilayah Asia Tenggara ataupun negara Singapura adalah GDP, Inflasi, Tingkat Suku Bunga, dan Trade Openness.

Pada awalnya Singapura memiliki kelemahan utama yaitu rendahnya akses modal, kurangnya profesionalisme pada perdagangan domestik, sewa tanah yang mahal, dan upah yang terlalu tinggi (Rekomendasi Working Group on Trading dalam Rachmawati dan Mutmainah, 2016). Namun, dibalik kelemahan tersebut Singapura menjadi negara yang sejahtera dengan mengandalkan Gross Domestic Product (GDP) yang tidak kalah dengan negara eropa barat. Dilihat pada peningkatan yang signifikan GDP singapura sejak merdeka. Dimulai pada $\$ 500$ per kapita dan naik hingga \$10.000 per kapita, lalu pada tahun 2007 berada pada angka $\$ 41,700$ (Porter dalam Rachmawati dan Mutmainah, 2016). Hal ini dapat menjadi faktor utama besarnya arus investasi langsung di Singapura. Adi (2016) menyatakan bahwa pada perekonomian negara, market size sendiri selalu mencerminkan ekspor, pendapatan nasional, serta pertumbuhan ekonomi. GDP sebagai unsur untuk melihat besarnya pertumbuhan ekonomi di suatu negara, juga digunakan sebagai alat ukur ekonomi mengenai besarnya pasar dalam periode jangka panjang dan nantinya akan menambah daya tarik investasi asing langsung masuk ke negara tersebut.

Tingkat inflasi singapura dikatakan cukup mendukung arus FDI. Pada tahun 2013 tingkat inflasi singapura berada pada $2 \%$ lalu pada tahun 
2014 turun menjadi sebesar $-0,01 \%$, tahun 2015 naik sebesar $-0,7 \%$, tahun 2016 naik menjadi $0,0 \%$, lalu pada tahun 2017 sampai tahun 2018 nilainya sama yaitu $0,05 \%$. Teori Cost-Push Inflation menjelaskan hubungan antara inflasi dan investasi, adanya kenaikan biaya produksi akan menyebabkan terjadinya penurunan penawaran agregat. Selain itu, tingginya harga-harga juga merupakan dampak dari kenaikan biaya produksi. Kenaikan biaya produksi sendiri muncul dikarenakan adanya akibat dari depresiasi nilai tukar, adanya dampak inflasi dari negara partner dagang, naiknya harga barang oleh pemerintah (administered prices), adanya guncangan sisi penawaran akibat adanya bencana alam sehingga distribusi menjadi terganggu, para buruh meminta kenaikan gaji, sifat industry yang monopolistis yang pada akhirnya menggunakan kekuatannya untuk menentukan harga lebih tinggi di pasar (Nopirin, 2013). Para kreditor akan terkena dampak dari naiknya tingkat inflasi, karena akses terhadap kredit akan lebih sulit sehingga arus masuk Foreign Direct Investment akan terhambat.

Selain dua instrumen ekonomi diatas ada tingkat suku bunga yang biasa dipakai pada penelitian untuk membuktikan pengaruhnya terhadap FDI. Keynes dalam Anwar, Kuswantoro, dan Dewi (2016) menyatakan bahwa dengan melihat Marginal Effeciency of Investment (MEI) yang menggambarkan mengenai hubungan investasi yang dijalankan oleh investor pada jangka waktu tertentu. Dan Marginal Effeciency of Capital (MEC) yang fokus terhadap hubungan antara hasil yang diharapkan yang berasal dari modal yang ditanamkan oleh pengusaha atau investor. Keterkaitan tersebut dikhususkan sebagai usaha yang mempunyai tingkat pengembalian modal relatif tinggi disbanding tingkat suku bunga berlaku. Dapat disimpulkan bahwa tingginya tingkat suku bunga akan menghambat masuknya investasi di suatu negara.

Variabel yang terakhir adalah variabel Trade Openness atau Keterbukaan Ekonomi. Menurut Hoang pada Septiantoro (2020) mengatakan dengan tingginya keterbukaan perdagangan (trade openness), dapat menyebabkan trade barrier menurun. Hal ini merupakan suatu kesempatan yang dapat dimanfaatkan oleh investor asing untuk dapat memanfaatkan keunggulan komparatif negara host country. Pada penelitian yang dilakukan oleh Ruth dan Syofyan (2014) menunjukkan bahwa Trade Openness negara singapura berpengaruh positif signifikan FDI. Dapat dikatakan bahwa salah satu elemen penting untuk menarik FDI yaitu Trade Openness.

Berdasarkan permasalahan yang telah diuraikan penulis diatas. Maka penulis melakukan penelitian berjudul "Analisis Faktor-Faktor Yang Mempengaruhi Foreign Direct Investment (FDI) Di Singapura Tahun 2004-2019”.

\section{TINJAUAN PUSTAKA}

\section{Investasi}

Dalam pelaksanaan pembangunan nasional haruslah mengejar ketertinggalan pembangunan dari negara lain. Suatu negara membutuhkan modal dana. Banyak cara untuk mendapatkan modal, salah satunya adalah investasi. Umumnya investasi diartikan sebagai suatu keputusan dimana suatu dana ditempatkan pada satu aset atau lebih selama jangka waktu tertentu yang diharapkan dapat menghasilkan peningkatan nilai investasi (Harianto dan Sudomo dalam Respati, 2020).

\section{Foreign Direct Investment (FDI)}

Penanaman modal asing secara langsung atau yang lebih dikenal sebagai Foreign Direct Investment adalah modal investasi yang terus digunakan untuk kegiatan produksi perusahaan (Todaro \& Smith, 2000). Penanaman modal asing langsung dapat diartikan suatu perusahaan disuatu negara yang membuka perusahaannya dinegara lain. Keistimewaan dari penanaman modal asing secara langsung ialah kegiatannya tidak hanya memindahkan bahan baku ataupun produknya saja melainkan juga manajemen perusahaannya. Perusahaan yang berada di negara lain biasanya disebut sebagai anak perusahaan yang biasanya struktur organisasi yang berlaku pun sama dengan induk perusahaannya. (Mudara \& Arianti, 2011) Jika dilihat dengan pandangan ekonomi FDI dikatakan sebagai proses menyuplai sumber daya modal, teknologi, ataupun sumber daya manusia antar negara namun tetap dibawah kuasa perusahaan utama. Ada persamaan antar 2 pandangan teori FDI baik dari pandangan investor asing dan pandangan negara tujuan FDI, yaitu adanya dominasi atas kepemilikan aset dan adanya pemindahan sebagian aset, produksi, serta kegiatan penjualan kepada negara tujuan (Moosa, 2002).

\section{Gross Domestic Product (GDP)}

Mankiw (2006) mengatakan GDP (Gross Domestic Product) atau yang biasa disebut sebagai Produk Domestik Bruto adalah salah satu perhitungan ekonomi yang dianggap penting dan pengkuran terbaik dalam memperkirakan kesejahteraan masyarakat. Sebab perhitungan GDP menggunakan jumlah pendapatan seluruh masyarakat dan jumlah belanja negara dalam hal pembelian barang dan jasa. Hubungan antara GDP dan FDI yaitu apabila pendapatan masyarakat tinggi yang sejalan dengan tingginya tingkat pendapatan nasional, hal ini akan memicu meningkatnya permintaan masyarakat terhadap barang dan jasa. Lalu dengan banyaknya permintaan ini perusahaan akan menuai lebih banyak keuntungan sehingga 
dorongan untuk melakukan investasi akan lebih besar (Sukirno, 2013).

\section{Inflasi}

Menurut Irham (2014) inflasi merupakan terjadinya depresiasi nilai mata uang pada suatu negara yang mengakibatkan melonjaknya harga barang yang berjalan secara sistematis. Teori mengenai inflasi seperti teori kuantitas yang membahas tentang penyebab perubahan harga saat tingginya jumlah uang beredar. Sedangkan penyebab lain dalam terjadinya inflasi dibahas pada teori strukturalis yang menyatakan bahwa lambatnya kegiatan ekspor, tingginya pertumbuhan penduduk, dan pendapatan perkapita dibanding jumlah produksi, yang mengakibatkan tingginya upah dan akhirnya membuat biaya produksi semakin tinggi. Menurut Ruth dan Syofyan (2014) pada saat terjadinya peningkatan inflasi yang mengakibatkan meningkatnya harga barang dan jasa, biaya bahan baku serta upah tenaga kerja yang didapatkan dari produksi otomatis juga meningkat. Disaat seperti ini perusahaan haruslah meningkatkan harga output. Disisi lain tingginya inflasi juga akan mengakibatkan daya beli masyarakat akan menurun dan berdampak pada kegiatan perdagangan yang rendah juga investor akan cenderung mengalami kerugian. Dengan serangkaian dampak ini, investor cenderung tidak akan melakukan investasi dinegara yang sedang mengalami tingkat inflasi yang tinggi untuk meminimalisir kerugian yang akan dialami.

\section{Tingkat Suku Bunga (Interest Rate)}

Tingkat suku bunga sendiri merupakan nilai dari pemakaian dana investasi. Tingkat suku bunga digunakan untuk menentukan keputusan investor untuk menginvestasikan uangnya atau memilih untuk menabung saja (Boediono, 2014). Menurut IMF, Lending Interest Rate atau suku bunga pinjaman merupakan suku bunga perusahaan simpanan lain yang melengkapi kebutuhan keuangan jangka pendek dan menengah dari unit swasta. Tarif yang dipakai bervariasi tergantung oleh kredibilitas peminjam dan tujuan pembiayaan. Tingkat suku bunga dapat digunakan sebagai cerminan biaya cost dari modal yang diperlukan investor pada waktu meminjam dana di bank host country. Rendahnya tingkat suku bunga dapat menjadi dorongan agar investor menanamkan modalnya atau bahkan meningkatkan modalnya untuk melakukan kegiatan investasinya (Astrid Mutiara Ruth, 2014).

\section{Trade Openness (Keterbukaan Perdagangan)}

Keterbukaan ekonomi dapat diartikan sebagai tidak adanya hambatan yang dihadapi dalam kegiatan perdagangan dan lancarnya arus permodalan antar negara. Keterbukaan ekonomi berdampak pada Trade Openness dan Financial Openness. Dampak positif yang ditimbulkan dari keterbukaan ekonomi melalui Trade Openness adalah semakin luasnya jangkauan pasar, tingginya persaingan dan efisiensi ekonomi, dan tingginya penyerapan tenaga kerja. Trade Openness atau yang sering disebut sebagai keterbukaan perdagangan diartikan sebagai kegiatan perdagangan yang meliputi kegiatan jual beli antar pihak atau negara dengan tidak adanya batasan. (Squalli \& Wilson, 2006)

Menurut Hoang dalam Septiantoro (2020) tingginya Trade Openness dapat menyebabkan hambatan perdagangan seperti tarif, kuota, subsidi, dan lainnya berkurang sehingga hal ini dimanfaatkan oleh investor asing untuk dapat memanfaatkan keunggulan komparatif negara tujuan investasi dengan melakukan reekspor atau pengiriman kembali barang impor ke negara asalnya maupun ke negara lainnya. Dengan ini dapat dikatakan bahwa dengan tingginya tingkat keterbukaan perdagangan disuatu negara akan lebih banyak menarik investor asing untuk melakukan kegiatan investasi langsung ke negara tersebut.

\section{METODE PENELITIAN}

Pada penelitian ini penulis memutuskan untuk menggunakan pendekatan kuantitatif yang objek penelitiannya memakai FDI negara Singapura (milyar US\$) sebagai variabel terikat, dimana untuk menganalisis variabel tersebut digunakan 4 variabel bebas yaitu GDP yang merupakan Gross Domestic Product Constant 2010 dan besarannya dinyatakan dalam bentuk milyar US\$, Inflasi, tingkat inflasi yang digunakan didapatkan dalam pengukuran Indeks Harga Konsumen (IHK). Variabel inflasi dinyatakan dalam bentuk (\%), Trade Openness dinyatakan dalam bentuk (\%), variabel ini diperoleh dari perhitungan total ekspor dijumlah dengan total impor lalu dibagi denga GDP, Tingkat Suku Bunga yang menggunakan Lending Interest Rate adalah suku bunga pinjaman yang dinyatakan dalam bentuk (\%). Data dari semua variabel diperoleh memakai teknik pengumpulan data studi kepustakaan. Data peneliti didapat dari website resmi World Bank.

\section{Teknik Analisis}

Penganalisisan pengaruh variabel bebas terhadap variabel terikat, digunakan analisis regresi linier berganda dengan asumsi BLUE (Best Linier Unbiased Estimate) agar diketahui koefisien pada persamaan tersebut tidak bias. oleh asistensi program computer olah data IBM SPSS (Statistic Program For Social Science) versi 23. Dengan model persamaan sebagai berikut :

Keterangan :

$$
Y=a+\beta_{1} X_{1}+\beta_{2} X_{2}+\beta_{3} X_{3}+\beta_{4} X_{4}
$$

$\begin{array}{ll}\mathrm{Y} & =\text { Variabel Terikat } \\ \mathrm{a} & =\text { Konstanta }\end{array}$


$\mathrm{X}_{1}, \mathrm{X}_{2}, \mathrm{X}_{3}, \mathrm{X}_{4}=$ Variabel Bebas

$\beta_{1}, \beta_{2}, \beta_{3}, \beta_{4} \quad=$ Koefisien Regresi

\section{HASIL DAN PEMBAHASAN}

\section{Uji Regresi Linier Berganda}

Berdasarkan hasil analisis dari olahan data diperoleh persamaan regresi linier berganda sebagai berikut:

$\mathrm{Y}=9.457 \mathrm{E}+11+0,409 \mathrm{X}_{1}+34592275.06 \mathrm{X}_{2}-$ $1,838 \mathrm{E}+11 \mathrm{X}_{3}-34185021.8 \mathrm{X}_{4}$

Berdasarkan persamaan yang didapat, dapat dijelaskan sebagai berikut:

$\beta_{0}$ : Nilai konstanta sebesar 9.457E+11 membuktikan apabila Gross Domestic Bruto $\left(\mathrm{X}_{1}\right)$, Inflasi $\left(\mathrm{X}_{2}\right)$, Tingkat Suku Bunga $\left(\mathrm{X}_{3}\right)$, dan Trade Openness $\left(\mathrm{X}_{4}\right)$ dianggap konstan dan arus masuk Foreign Direct Investment (Y) akan naik sebesar $9.457 \mathrm{E}+11 \%$

$\beta_{1}$ : Nilai 0,409 menunjukkan bahwa apabila Gross Domestic Product $\left(\mathrm{X}_{1}\right)$ naik sebesar 1 milyar dollar maka nilai arus masuk Foreign Direct Investment di Singapura (Y) akan naik sebesar $0,409 \%$ dengan asumsi $\mathrm{X}_{2}, \mathrm{X}_{3}$, dan $\mathrm{X}_{4}$ konstan.

$\beta_{2}$ : Nilai 34592275.06 menunjukkan bahwa apabila Inflasi $\left(\mathrm{X}_{2}\right)$ naik sebesar $1 \%$ (persen) maka nilai arus masuk Foreign Direct Investment di Singapura (Y) akan naik sebesar $34592275.06 \%$ dengan asumsi konstannya $X_{1}$, $\mathrm{X}_{3}$, dan $\mathrm{X}_{4}$ konstan.

$\beta_{3}$ : Nilai $-1,838 \mathrm{E}+11$ menunjukkan bahwa apabila Lending Interest Rate $\left(\mathrm{X}_{3}\right)$ turun sebanyak $1 \%$ (persen) akibatnya arus masuk Foreign Direct Investment di Singapura (Y) akan naik sebesar $1,838 \mathrm{E}+11 \%$ dengan asumsi konstannya $\mathrm{X}_{1}, \mathrm{X}_{2}$, dan $\mathrm{X}_{4}$.

$\beta_{4}$ : Nilai -34185021.8 menunjukkan bahwa apabila Trade Openness $\left(\mathrm{X}_{4}\right)$ turun sebesar $1 \%$ (persen) maka nilai arus masuk Foreign Direct Investment di Singapura (Y) akan naik sebesar $34185021.8 \%$ dengan asumsi konstannya $\mathrm{X}_{1}$, $\mathrm{X}_{2}$, dan $\mathrm{X}_{3}$.

\section{Uji Asumsi Klasik}

Pengujian asumsi klasik dilakukan untuk mendapatkan hasil estimasi BLUE (Best Linier Unbiased Estimator) atau persamaan regresi linear tidak bias maka hasil estimasi haruslah memenuhi beberapa asumsi yang berkaitan. Apabila ada salah satu uji asumsi yang dilanggar atau tidak sesuai dengan ketentuannya, maka persamaan regresi yang diperoleh tidak bersifat BLUE. Hal ini akan berdampak pada pengambilan keputusan hipotesis dengan Uji F dan Uji T menjadi bias. Ada tiga uji yang harus dilakukan dan terbebas agar persamaan regresi bersifat BLUE, diantaranya adalah:

\section{Uji Autokorelasi}

Untuk melihat apakah terjadi atau tidaknya gejala autokorelasi dapat ditentukan dengan nilai DW atau yang dikenal dengan Durbin Watson. Hasil yang didapat dari pengujian data adalah sebagai berikut:

\section{Tabel 1. Hasil Uji Autokorelasi}

\begin{tabular}{|c|c|c|c|c|c|}
\hline & $\mathrm{R}$ & R Square & $\begin{array}{c}\text { Adjusted R } \\
\text { Square }\end{array}$ & $\begin{array}{l}\text { Std. Error of the } \\
\text { Estimate }\end{array}$ & $\begin{array}{l}\text { Durbin- } \\
\text { Watson }\end{array}$ \\
\hline 1 &, $963^{\mathrm{a}}$ &, 928 &, 899 & 8750891606 & 2,135 \\
\hline
\end{tabular}

Sumber: Hasil Output SPSS IBM Versi 23 (2021)

Pada uji autokorelasi pada penelitian ini diperoleh nilai $D W$ test sebesar 2,135. Dalam persamaan ini jumlah variabel bebas (k) yang digunakan adalah sebanyak 4 variabel yang meliputi Gross Domestic Product, Inflasi, Tingkat Suku Bunga, dan Trade Openness, dan banyaknya data (n) yang digunakan adalah 15 data sehingga didapatkan nilai $D W$ tabel adalah sebesar $\mathrm{dL}=0,6852$ dan $\mathrm{dU}=$ 1,9774. Maka dapat diartikan bahwa tidak ditemukan gejala autokorelasi karena nilai $D W$ berada diantara nilai $\mathrm{dL}$ dan $\mathrm{dL}$ yang berarti tanpa kesimpulan atau berada pada daerah keragu-raguan dan dapat dilanjutkan ke uji selanjutnya.

\section{Uji Multikolinieritas}

Tabel 2. Hasil Uji Multikolinieritas

\begin{tabular}{llrrrr}
\hline & & \multicolumn{2}{c}{ Unstandardized Coefficients } & \multicolumn{2}{c}{ Collinearity Statistics } \\
\cline { 2 - 6 } \multicolumn{1}{c}{ Model } & \multicolumn{1}{c}{$\mathrm{B}$} & \multicolumn{1}{c}{ Std. Error } & Tolerance & VIF \\
\hline 1 & (Constant) & $9,457 \mathrm{E}+11$ & $4,416 \mathrm{E}+11$ & & \\
& GDP &, 409 &, 116 &, 138 & 7,226 \\
& Inflasi & 34592275,06 & 1889447476 &, 332 & 3,016 \\
& Tingkat Suku Bunga & $-1,838 \mathrm{E}+11$ & 173472940,7 &, 106 & 9,453 \\
& Trade Openness & $-34185021,8$ & 2094223153 &, 576 & 1,735 \\
\hline
\end{tabular}

Sumber : Hasil Output SPSS IBM Versi 23 (2021) 
Dalam tabel 1, dapat dilihat bahwa keempat variabel bebas tidak terjadi gejala multikolinieritas. Karena semua nilai VIF dari model yang digunakan kurang dari 10 dan nilai Tolerance lebih dari 0,10. Maka dapat diputuskan bahwa pengujian dapat dilanjutkan.

\section{Uji Heterokedastisitas}

Tabel 3. Hasil Uji Heterokedastisitas

\begin{tabular}{cllc}
\hline & & & Unstandardized Residual \\
\hline \multirow{2}{*}{ Spearman's rho } & GDP & Sig. (2-tailed) &, 761 \\
& Inflasi & Sig. (2-tailed) &, 140 \\
& Tingkat Suku Bunga & Sig. (2-tailed) &, 844 \\
& Trade Openness & Sig. (2-tailed) &, 558 \\
& Unstandarized Residual & Sig. (2-tailed) & - \\
\hline
\end{tabular}

Sumber : Hasil Output SPSS IBM Versi 23 (2021)

Hasil uji heterokedastisitas menunjukkan bahwa semua variabel bebas memiliki nilai Sig. (2tailed) lebih dari 0,05. Artinya, semua variabel terbebas dari uji heterokedastisitas, dan dapat dilanjutkan ke uji selanjutnya.

Uji $\mathbf{R}^{2}$

Tabel 4. Koefisien Determnasi

\begin{tabular}{|c|c|c|c|c|}
\hline Model & $\mathrm{R}$ & R Square & Adjusted R Square & Std. Error of the Estimate \\
\hline 1 &, $963^{\mathrm{a}}$ & ,928 &, 899 & 8750891606 \\
\hline
\end{tabular}

Sumber : Hasil Output SPSS IBM Versi 23 (2021)

Dapat dilihat pada hasil output diatas, nilai $\mathrm{R}^{2}$ sebesar 0,928. Maka dapat disimpulkan bahwa kemampuan variabel bebas dalam menjelaskan Uji F variabel terikat cukup besar yakni sebesar 92,8\% dan sisanya sebesar 7,2\% dijelaskan oleh faktor lain selain model yang digunakan.

Tabel.5 Hasil Uji Simultan F (ANOVA)

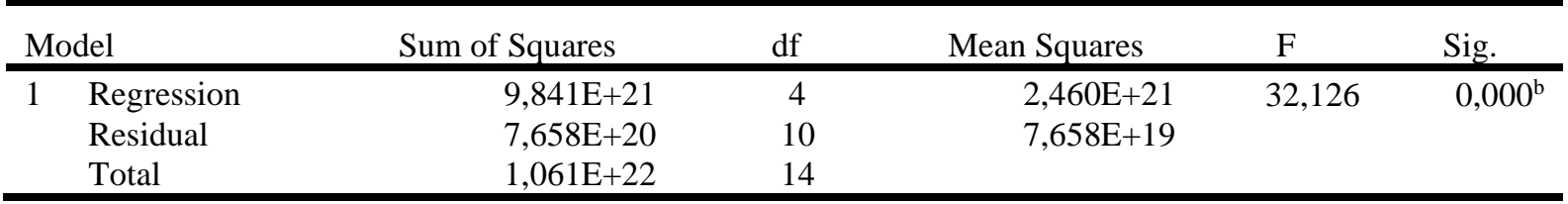

Sumber : Hasil Output SPSS IBM Versi 23 (2021)

Dapat dilihat pada tabel diatas diperoleh nilai f hitung sebesar 32,126 dengan tingkat signifikan sebesar $0,000^{\mathrm{b}}$, sedangkan nilai f tabel $(\alpha=0,05)$ yang diperoleh berdasarkan degree of freedom $\left(\mathrm{df}_{1}\right)$ yang meliputi 4 (jumlah variabel bebas/k) dan $\left(\mathrm{df}_{2}\right)$ yaitu 10 (n-k-1) yaitu sebesar 3,478. dari hasil tersebut dapat disimpulkan bahwa nilai $\mathrm{f}$ hitung $32,126 \geq \mathrm{f}$ tabel 3,478 . dapat ditarik kesimpulan bahwa Gross Domestic Product, Inflasi, Tingkat Suku Bunga, dan Trade Openness secara simultan atau serempak berpengaruh terhadap Foreign Direct Investment di Singapura.

Uji T

Penggunaan uji t statistic adalah untuk mengetahui pengaruh dari setiap variabel bebas terhadap variabel terikat secara individu.

Tabel.5 Uji t (Parsial)

\begin{tabular}{|c|c|c|c|c|c|c|}
\hline \multirow{2}{*}{\multicolumn{2}{|c|}{ Model }} & \multicolumn{2}{|c|}{ Unstandardized Coefficients } & \multirow{2}{*}{$\begin{array}{c}\text { Standardized } \\
\text { Coefficients }\end{array}$} & \multirow[b]{2}{*}{$\mathrm{t}$} & \multirow[b]{2}{*}{ Sig. } \\
\hline & & $\mathrm{B}$ & Std. Error & & & \\
\hline \multirow[t]{5}{*}{1} & (Constant) & $9,457 \mathrm{E}+11$ & $4,416 \mathrm{E}+11$ & & 2,141 &, 000 \\
\hline & GDP & ,409 &, 116 & ,809 & 3,542 & , 199 \\
\hline & Inflasi & 34592275,06 & 1889447476 &, 003 & ,018 &, 004 \\
\hline & Tingkat Suku Bunga & $-1,838 \mathrm{E}+11$ & 173472940,7 &,- 277 & $-2,475$ &, 000 \\
\hline & Trade Openness & $-34185021,8$ & 2094223153 &,- 051 &,- 197 &,- 779 \\
\hline
\end{tabular}

Sumber : Hasil Output SPSS IBM Versi 23 (2021) 
Pada perhitungan secara parsial variabel GDP terhadap Foreign Direct Investment di Singapura diperoleh nilai t hitung sebesar 3,542 sedangkan nilai t tabel $(\alpha / 2=0,025)$ yang diperoleh dengan degree of freedom (df) 10 (n-k-1) adalah sebesar 2,22814. Maka nilai t hitung 3,542 > t tabel 2,22814 dan nilai Sig sebesar 0,0005 yang artinya HO ditolak dan HI diterima. Artinya secara parsial variabel Gross Domestic Product (GDP) berpengaruh positif signifikan terhadap Foreign Direct Investment di Singapura.

Pada perhitungan secara parsial variabel Inflasi terhadap Foreign Direct Investment di Singapura diperoleh nilai t hitung sebesar 0,018 sedangkan nilai t tabel $(\alpha / 2=0,025)$ yang diperoleh dengan degree of freedom (df) 10 (n-k-1) adalah sebesar 2,22814. Dapat disimpulkan bahwa nilai $\mathrm{t}$ hitung 0,018< t tabel 2,22814 dan nilai Sig sebesar 0,986 yang artinya HO diterima dan HI ditolak. Artinya secara parsial variabel Inflasi tidak berpengaruh secara signifikan terhadap Foreign Direct Investment di Singapura.

Pada perhitungan secara parsial variabel Tingkat Suku Bunga terhadap Foreign Direct Investment di Singapura diperoleh nilai $\mathrm{t}$ hitung sebesar $-2,475$ sedangkan nilai t tabel $(\alpha / 2=0,025)$ yang diperoleh dengan degree offreedom (df) 10 (n$\mathrm{k}-1$ ) adalah sebesar 2,22814. Maka nilai t hitung 2,475 > t tabel 2,22814 dan nilai Sig sebesar 0,033 yang artinya $\mathrm{HO}$ ditolak dan $\mathrm{HI}$ diterima. Artinya secara parsial variabel Tingkat Suku Bunga berpengaruh negatif signifikan terhadap Foreign Direct Investment di Singapura.

Pada perhitungan secara parsial variabel Trade Openness terhadap Foreign Direct Investment di Singapura diperoleh nilai t hitung sebesar -0,197 sedangkan nilai t tabel $(\alpha / 2=0,025)$ yang diperoleh dengan degree of freedom (df) 10 (n-k-1) adalah sebesar 2,22814. Dapat disimpulkan bahwa nilai $\mathrm{t}$ hitung $-0,197<$ t tabel 2,22814 dan nilai Sig sebesar 0,848 yang artinya $\mathrm{H} 0$ diterima dan $\mathrm{HI}$ ditolak. My Artinya secara parsial variabel Trade Openness tidak berpengaruh secara signifikan terhadap Foreign Direct Investment di Singapura.

\section{Pengaruh Gross Domestic Product Terhadap Foreign Direct Investment di Singapura}

Berdasarkan hasil uji hipotesis yang menunjukkan bahwa variabel GDP $\left(\mathrm{X}_{1}\right)$ berpengaruh positif signifikan terhadap Foreign Direct Investment di Singapura (Y). Artinya, apabila Gross Domestic Product meningkat maka arus masuk Foreign Direct Investment di Singapura juga akan meningkat. Pada teori Market Size dan daya beli masyarakat pada suatu negara oleh Sukirno (2013), tingginya daya beli masyarakat sering dikaitkan dengan tingginya pendapatan nasional maupun pertumbuhan ekonomi. Apabila pertumbuhan ekonomi pada suatu negara menunjukkan arah yang baik, hal tersebut dapat menjadi salah satu faktor yang dapat menarik investor asing untuk melakukan investasi asing langsung dengan jangka waktu yang Panjang karena harapan positif atas kegiatan perkonomian pada negara tujuan investasi. Sejalan dengan penelitian yang dilakukan oleh Septiantoro, Hasanah, Alexandi, Nugraheni (2020) yang menunjukan hasil bahwa Gross Domestic Product berpengaruh positif signifikan terhadap Foreign Direct Investment di ASEAN

\section{Pengaruh Inflasi Terhadap Foreign Direct Investment di Singapura}

Berdasarkan hasil uji hipotesis, variabel Inflasi $\left(\mathrm{X}_{2}\right)$ tidak berpengaruh secara signifikan terhadap Foreign Direct Investment di Singapura (Y). Sama seperti penelitian oleh Tambunan et al. (2015) yang menunjukkan hasil bahwa variabel inflasi tidak berpengaruh signifikan terhadap Foreign Direct Investment. Hasil ini dapat diterima karena konfisi inflasi pada suatu negara bukan satusatunya faktor yang dapat menjadi penghalang bagi investor asing untuk melakukan investasi pada negara tujuan investasi. Inflasi tidak memengaruhi investor asing karena peningkatan harga lebih tinggi dibanding biaya produksi yang dikeluarkan, sehingga investor masih memperoleh keuntungan.

\section{Pengaruh Tingkat Suku Bunga Terhadap Foreign Direct Investment di Singapura}

Berdasarkan hasil uji hipotesis yang menunjukkan bahwa variabel Tingkat Suku Bunga $\left(\mathrm{X}_{3}\right)$ berpengaruh negatif signifikan terhadap FDI di Singapura (Y). Artinya tingginya tingkat suku bunga disuatu negara berdampak pada dorongan untuk melakukan kegiatan investasi akan semakin menurun. Pada kurva Marginal Efficiency of Investment, menjabarkan bahwa investor akan melakukan investasi jika tingkat pegembalian modal lebih tinggi atau sama dengan suku bunga. Ruth dan Syofyan (2014) menyatakan bahwa tingkat suku bunga dapat mencerminkan biaya/cost dari modal yang diperlukan investor pada saat menggunakan ataupun meminjam dana pada lembaga keuangan di host country. Sama dengan hasil penelitian Ruth dan Syofyan (2014) bahwa lending interest rate berpengaruh negatif signifikan terhadap Foreign Direct Investment di 7 negara ASEAN.

\section{Pengaruh Trade Openness Terhadap Foreign Direct Investment di Singapura}

Hasil uji hipotesis yang menunjukkan bahwa variabel Trade Openness $\left(\mathrm{X}_{4}\right)$ tidak berpengaruh secara signifikan terhadap Foreign Direct Investment di Singapura (Y). sama seperti penelitian yang dilakukan oleh Ruth dan Syofyan (2014) yaitu keterbukaan perdagangan tidak berpengaruh secara signifikan terhadap FDI di beberapa negara. 


\section{KESIMPULAN}

Kesimpulan yang dapat diambil adalah sebagai berikut:

1. GDP berpengaruh signifikan positif terhadap Foreign Direct Investment di Singapura.

2. Inflasi tidak mempunyai pengaruh signifikan terhadap Foreign Direct Investment di Singapura.

3. Tingkat Suku Bunga (Lending Interest Rate) berpengaruh signifikan negatif dengan Foreign Direct Investment di Singapura.

4. Trade Openness tidak mempunyai pengaruh yang signifikan pada Foreign Direct Investment di Singapura.

\section{SARAN}

Berdasarkan kesimpulan yang tertera diatas, berikut ini saran yang dianjurkan oleh penulis:

1. Pemerintah dapat menciptakan iklim investasi yang baik dengan cara: a. peningkatan Gross Domestic Product maupun pertumbuhan ekonomi dapat menunjang perbaikan sistem perekonomian di suatu negara; b. Pemerintah juga diharapkan mampu mengendalikan tingkat suku bunga.

2. Penelitian ini dapat dijadikan rekomendasi dan keputusan bagi investor negara lain yang ingin melakukan investasi di negara Singapura. Bagi peneliti selanjutnya dapat memperluas jumlah sampel yang lebih besar, dapat menambah variabel diluar variabel penelitian ini, serta dapat menambah data yang lebih baru. Sehingga dapat menyempurnakan banyak penelitian sebelumnya.

\section{DAFTAR PUSTAKA}

Adi, R. D., \& Bagus. (2020). Pengaruh BI Rate, Indeks Harga Saham Gabungan, Kurs, Serta Nilai Ekspor Terhadap Foreign Direct Investment dan PMDN di Indonesia.

ASEAN Investment Report. (2019). ASEAN Investment Report 2019. In ASEAN Secretariat (Issue 1).

Astrid Mutiara Ruth, S. S. (2014). Faktor Penentu Foreign Direct Investment di ASEAN-7; Analisis Data Panel, 2000-2012. Media Ekonomi, 22(1).

Boediono. (2014). Ekonomi Makro ed.4. Yogyakarta: BP.

Cep Jandi Anwar, Kuswantoro, S. F. D. (2016). Faktor-Faktor Yang Mempengaruhi Foreign Direct Investment (Fdi) Di Kawasan Asia Tenggara. Media Trend, 11(2), 175. https://doi.org/10.21107/mediatrend.v11i2.16 21

Geringer, J., Ball, D., Minor, M., \& McNett, J. (2014). Bisnis Internasional Buku 1.

Irham;, F. (2014). Manajemen Keuangan
Perusahaan dan Pasar Modal.

Lumadya, A. (2016). Ukuran Pasar Ukuran Pasar (Market Size) Dan Investasi Asing Langsung Di Asean. Jae (Jurnal Akuntansi Dan Ekonomi), 1(1), 26. https://doi.org/10.29407/jae.v1i1.430

Mankiw, N. G. (2006). The macroeconomist as scientist and engineer. Journal of Economic Perspectives, 20(4), 29-46.

Moosa, I. A. (2002). Foreign direct investment: theory, evidence, and practice. In Choice Reviews Online (Vol. 40, Issue 01). https://doi.org/10.5860/choice.40-0422

Mudara, I., \& ARIANTI, F. (2011). Pengaruh Produk Domestik Bruto, Suku Bunga, Upah Pekerja, dan Nilai Total Ekspor Terhadap Investasi Asing langsung di Indonesia (19902009). Universitas Diponegoro.

Mutmainah, D., \& Rachmawati, N. (2016). ASEAN sebagai Instrumen Adaptasi Singapura terhadap Globalisasi. Transformasi Global, 1(1), 55-73. http://transformasiglobal.ub.ac.id/index.php/t rans/article/view/11

Nopirin, P. D. (2013). Ekonomi Internasional Edisi Ketiga. Yogyakarta: BPFE.

Septiantoro, A. A., Hasanah, H., Alexandi, M. F., \& Nugraheni, S. R. W. (2020). Apakah Kualitas Institusi Berpengaruh pada Arus Masuk FDI di ASEAN? Jurnal Ekonomi Dan Pembangunan Indonesia, 20(2), 146-159. https://doi.org/10.21002/jepi.v20i2.1132

Squalli, J., \& Wilson, K. (2006). A new approach to measuring trade openness. Economic \& Policy Research Unit Working Paper, 6(07).

Sukirno, S. (2013). Pengantar Teori Ekonomi Makro Edisi Ketiga. Jakarta: PT Radja Grafindo Perkasa.

Tambunan, R. S., Yusuf, Y., \& Mayes, A. (2015). Pengaruh Kurs, Inflasi, Libor Dan Pdb Terhadap Foreign Direct Invesment (Fdi) Di Indonesia. Jurnal Ekonomi, 23(1). https://je.ejournal.unri.ac.id/index.php/JE/arti cle/view/5781

Todaro, M. P., \& Smith, S. C. (2000). Economic Development Pearson Education Limited. Essex. England, 7.

Villafuerte, J., \& Yap, J. T. (2015). Managing Capital Flows in Asia: An Overview of Key Issues. SSRN Electronic Journal. https://doi.org/10.2139/SSRN.2709325 